
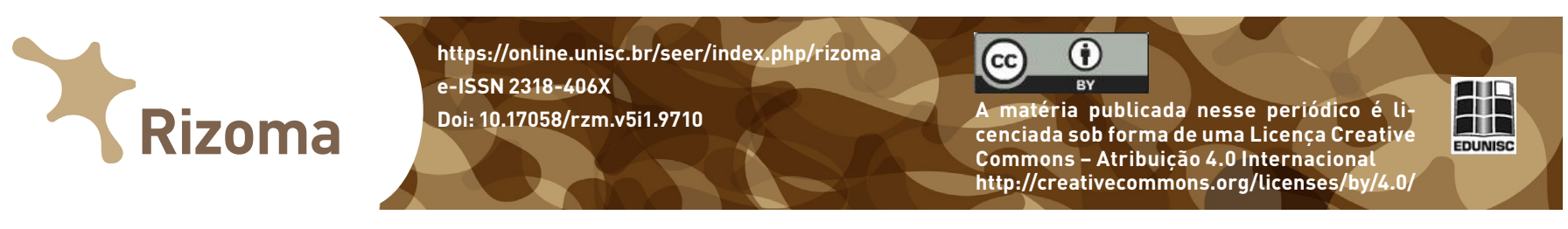

\title{
Entrevistas em série
}

Resumo: As séries de televisão reúnem orçamentos generosos, expectativas diferenciadas da audiência, equipes de produção criativas e obras de eminente qualidade estética. Em destaque, as séries que estreitam a relação entre ficção e realidade, fazendo uso de recursos narrativos que, historicamente, eram mais identificados com o gênero documentário. Em Band of Brothers, a entrevista opera como indicador de autenticidade, como momento de ativação da memória e como elo entre passado e presente.

Palavras-chave: entrevista; série; televisão; cinema.

Jair Giacomini'

\section{Entrevistas en serie}

Resumen: Las series de televisión combinan presupuestos generosos, expectativas diferenciadas de la audiencia, equipos de producción creativos y obras de gran calidad estética. En particular, las series que estrechan la relación entre ficción y realidad, haciendo uso de recursos narrativos que, históricamente, eran más identificados con el género documental. En Band of Brothers, la entrevista opera como indicador de autenticidad, como momento de activación de la memoria y como enlace entre pasado y presente.

Palabras clave: Entrevista, series, televisión, cine.

\section{Serial interviews}

\begin{abstract}
Television series bring together generous budgets, differentiated expectations of the audience, creative production teams, and works of immeasurable aesthetic quality. In highlight, the series that narrow the relation between fiction and reality, making use of narrative resources that, historically, were more identified with the documentary genre. In Band of Brothers, the interview operates as an indicator of authenticity, as a moment of activation of memory and as a link between past and present.
\end{abstract}

Keywords: interview, series, television, cinema.

\section{As "séries de qualidade"}

Desde Twin Peaks (1990-1991), as séries de televisão constituem o novo espaço da arte cinematográfica. Melhor dizendo, se durante muitos anos, o cinema foi o fiel depositário das artes da imagem em movimento e 

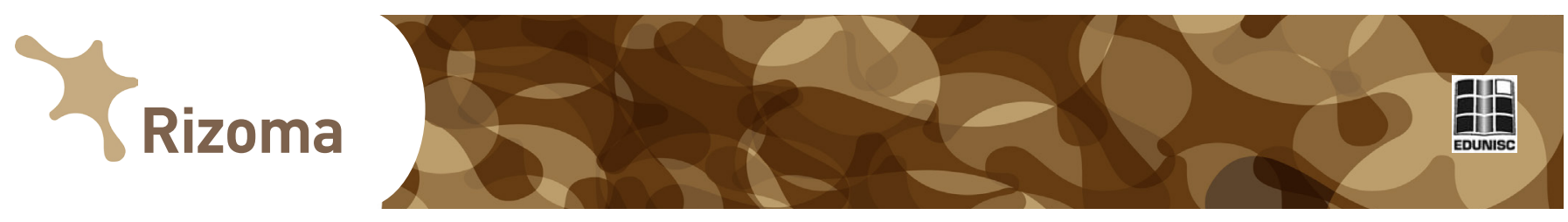

do som enquanto a televisão constituía a mídia do quanto-mais-audiênciamelhor-não-importa-a-qualidade, os investimentos - de recursos e de criatividade - nas séries proporcionaram uma renovação dos olhares. Literal e figurativamente falando, passamos a ver a televisão com outros olhos. Uma nova era surge, tanto para telespectadores quanto para realizadores - aqui compreendidos tanto aqueles das áreas criativas quanto aqueles envolvidos na engenharia econômica que move a máquina televisiva.

Sempre se acusou - não sem motivos - a televisão de mirar somente na audiência. Sempre se recobriu o cinema com a película da aura artística. Raras vezes, em especial no meio acadêmico, se considerou que o cinema também é pai de obras nada artísticas e que a televisão poderia contrariar seu mal traçado destino de mídia menor.

A nova era da televisão, a era em que assistir à televisão passou a ser "um programa digno" não foi inaugurada com os "telecines". Esses canais por assinatura, apesar de conectar em seu nome as duas mídias, não foram além da exibição de filmes durante vinte e quatro horas por dia, nada fizeram além de reexibir, na tela pequena, obras produzidas originalmente para a tela grande. A nova era a qual nos referimos surge quando começam a ser produzidas e exibidas as "séries de qualidade". Assim as chamamos aqui, mas a título de exercício, outras denominações poderiam ser dadas, tais como: séries cinematográficas; séries com qualidade cinematográfica; séries televisivas com um toque de cinema; cinema em forma de séries televisivas; cinema seriado exibido na televisão; televisão com cinema; televisão mais cinema. Esse exercício serve também para demonstrar como é complexo encontrar uma expressão que defina exatamente o que é preciso - seria preciso um termo que marcasse a diferença entre essas "séries de qualidade" e as outras séries produzidas pela televisão que não possuem o mesmo apuro estético e criativo; um termo que também assinalasse o fato de serem pensadas e produzidas diretamente para a televisão; e ainda um termo que apontasse que tais produtos televisivos herdam do (bom) cinema a inventividade, o refinamento, o cuidado com os detalhes, ou seja, aquela série de elementos que costumamos reconhecer como autenticadores do cinema como arte.

A relação das "séries de qualidade" da televisão com o cinema se dá também por conta da migração, temporária ou definitiva, de profissionais originalmente "de cinema" para trabalhar em produções cuja primeira janela será agora a televisão. É justamente o caso de David Lynch, um dos criadores, junto com Mark Frost, de Twin Peaks. Conhecido até então por seus filmes pouco convencionais, Lynch traz para a televisão um sopro de inovação que vai fazer escola nas décadas seguintes, tanto na TV norte-americana quanto na de outros países, entre eles o Brasil.

A trama de Twin Peaks tem como ponto de partida o assassinato da colegial Laura Palmer na cidade ficcional que dá nome à série e a subsequente investigação do crime pelo agente do FBI Dale Cooper. O episódio piloto estreou na ABC (televisão aberta norte-americana) em 8 de abril de 1990 e sua primeira temporada teve mais sete episódios. Já a segunda temporada, com 22 episódios, foi ao ar até 10 de junho de 1991. Twin Peaks foi um dos 

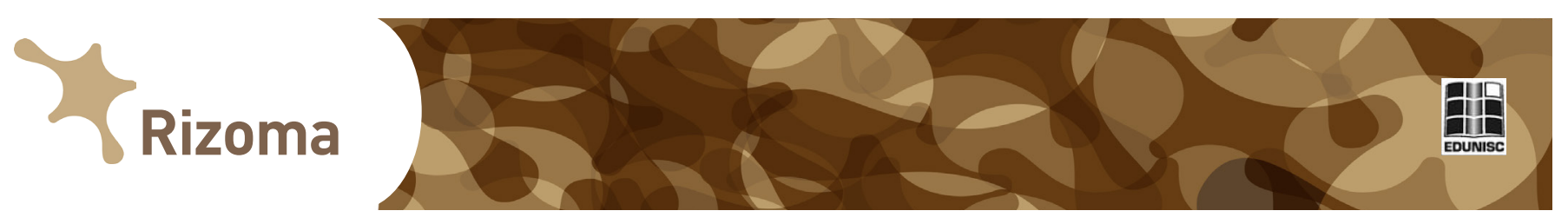

programas mais assistidos da década de 1990 e teve grande sucesso de crítica, tanto nos Estados Unidos quanto nos demais países em que foi exibida. A série acabou se tornando um cult e, como já dissemos, referência para futuras séries de televisão. É a partir dela que canais por assinatura, como a $\mathrm{HBO}$, se antenaram para o evidente filão mercadológico que se desenhava e para o desejo latente do público por obras como aquela.

Fazendo jus ao estilo David Lynch, Twin Peaks não poderia deixar de ter um toque surrealista. Mas é por uma sensação de "fria realidade" que Twin Peaks marca o cenário televisivo. Essa atmosfera contrastou com quase tudo o que vinha sendo apresentado pela televisão. O clima de realidade nessa produção é construído, entre outros elementos, por personagens complexos (contrastando com os personagens geralmente planos que permeavam a teledramaturgia), gravações em locação (em oposição ao artificialismo dos cenários em estúdio) e um ritmo mais lento (a intensificação do real advém da espera e não mais da rápida sobreposição de acontecimentos; com Twin Peaks aprendemos a respirar, mesmo que uma respiração asfixiante).

\section{Conexão real}

A fria realidade, ou melhor dizendo, a busca por uma espécie de ligação direta com a realidade vai se tornar uma das correntes mais promissoras das séries televisivas. Uma estratégia para atrair a atenção da audiência pela intensidade de identificação do espectador com um mundo do qual ele também faz parte, ou pelo menos, do qual ele poderia fazer. $\mathrm{O}$ empenho por alcançar um alto grau de realismo não se dá, claro, apenas pela dimensão da imagem; também, e na mesma medida, está o som. Diálogos (sempre o calcanhar de Aquiles dos roteiros de ficção!) e ambientação sonora naturalistas, aliados ao uso parcimonioso e consciente da trilha musical over são procedimentos perseguidos pelas equipes de produção que optaram pelo caminho realista para suas séries.

Evidentemente, os padrões de um possível realismo da imagem (e do som) sofrem variação de época para época. A transparência da montagem, por exemplo, foi durante muitas décadas a norma estética de afirmação do cinema como sendo uma janela para o mundo. Em contrapartida, os jump cuts e a quebra da quarta parede da Nouvelle Vague expuseram o truque da transparência - esta é "denunciada" como ardil construído através de um conjunto de regras que, de um lado, foi estabelecido pela indústria cinematográfica e, de outro, aceito tácita e prazerosamente pelo público.

Dando provas à tese da percepção mutante, nos últimos anos, a quebra, o jump cut, a câmera não mão e o olhar direcionado diretamente para a câmera tornaram-se justamente o oposto do que eram quando surgiram. Agora, esses recursos passam a ser identificados (por realizadores e por espectadores) como índices de proximidade com o real. Essa câmera "jornalística" ou "documentária", que sobe as ruas estreitas da favela, acabou por se impor como a nova janela para o mundo real. O que antes turbava a visão 

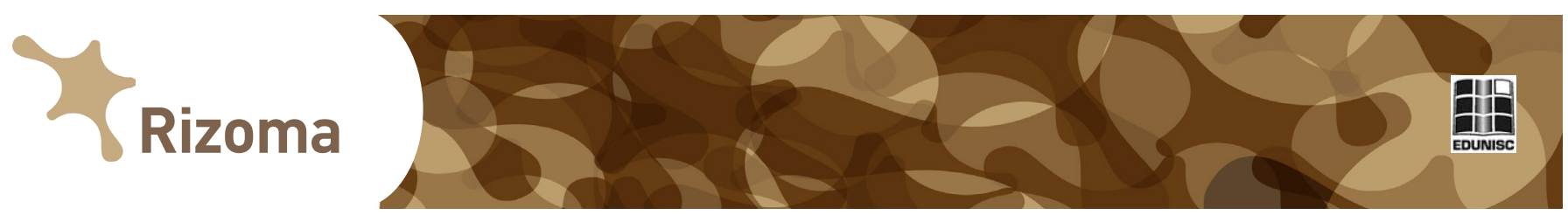

agora ajuda o espectador a sentir que ele está muito perto daquilo que é mostrado. Basta citarmos exemplos próximos como Tropa de Elite (pelo gênero ficção), Profissão Repórter (pelo jornalismo) e Falcão, meninos do tráfico (pelo documentário).

\section{Um documentário é um documentário}

Mais ou menos na mesma época em que Goddard e seus colegas quebravam as regras da ficção cinematográfica, os documentaristas encontravam nas câmeras mais leves e nos gravadores portáteis de áudio avanços tecnológicos que propiciaram novas experiências estéticas e novas propostas éticas do fazer documentário. Assim, os norte-americanos do cinema direto se afastaram do objeto e abdicaram do narrador over enquanto os franceses do cinema vérité entraram no quadro para interagir com seus objetos/personagens, seja para realizar entrevistas, seja para provocá-los de outras formas, mais ou menos sutis, menos ou mais éticas.

Ouvimos, com bastante frequência nos últimos tempos, que, para reforçar o caráter da verossimilhança, a ficção trouxe para dentro do seu espaço os recursos do documentário. Isto está certo, mas apenas em parte. Está certo quando consideramos que estes recursos estilísticos - câmera trêmula e assemelhados - são de fato utilizados pelos documentaristas. Mas não é toda a verdade, se lembrarmos que tais procedimentos são marcas de certos modos de documentário ${ }^{2}$, especialmente, o observativo (que corresponde ao direto) e o participativo (que corresponde ao vérité), e não "do" documentário enquanto gênero, dado que não existe "uma" linguagem do documentário, não existe "um" modo de fazer documentário. Importa ressaltar aqui que tais recursos, ao serem utilizados pela ficção audiovisual, têm operado sim como índices de uma estética realista - e, possivelmente, vão continuar a ser utilizados por um bom tempo, pelo menos até que a percepção de realizadores e de espectadores identifiquem outras formas, ainda mais eficientes, de aproximação entre o "mundo real" e o universo representado na obra audiovisual.

\section{$O$ caso Band of Brothers}

Adaptado do bestseller de Stephen E. Ambrose, Band of Brothers conta a história da Companhia Easy, integrante da $101^{\text {a }}$ divisão de paraquedistas do exército norte-americano, na Segunda Guerra Mundial. Coproduzida por Steven Spielberg e Tom Hanks (também codiretor), foi exibida em 2001 nos EUA pela $\mathrm{HBO}$ e em diferentes canais de televisão em diversos outros países no mesmo ano e nos subsequentes. A versão em DVD traz na sinopse da sua contracapa o seguinte trecho: "baseada nas entrevistas dos sobreviventes, diários e cartas dos soldados, a produção relata as experiências dos homens que conheceram a coragem e o medo, sofreram incontáveis baixas e acabaram tornando-se lendas". 

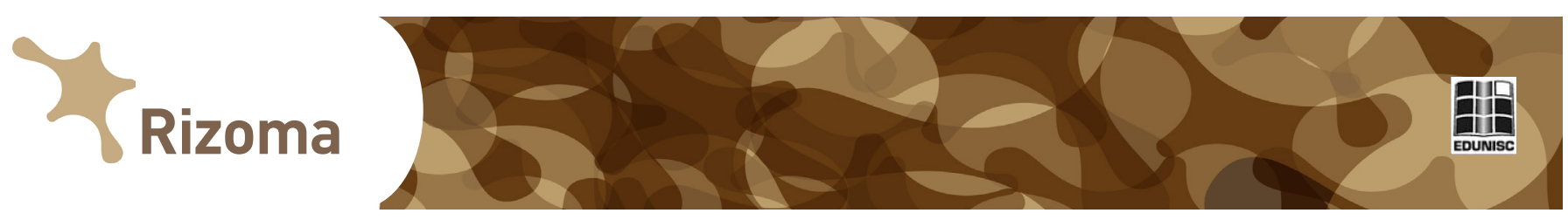

Interessa-nos aqui, inicialmente, selecionar e aproximar os termos "baseada nas entrevistas dos sobreviventes" e "acabaram tornando-se lendas". De fato, para que personagens reais tornem-se lendas, é necessária a ativação de uma série de representações que, ao longo do tempo, se multipliquem e se cristalizem no imaginário social. A série de Spielberg e Hanks, sob esse ponto de vista político da construção do imaginário, é, sem dúvida, uma obra audiovisual que surge para reforçar as representações que permitem que pessoas desconhecidas do grande público alcancem o status de lenda. Possivelmente, nos Estados Unidos, a Companhia Easy já estivesse presente em certo grau no imaginário popular. Mas nos demais países para os quais a série foi exportada, podemos dizer que a maior parte dos espectadores de Band of Brothers desconhecia a história dos sobreviventes e até mesmo a existência da Companhia Easy. É, portanto, justamente através dessa série televisiva que aqueles paraquedistas norte-americanos da Segunda Guerra, vivos ou mortos, podem potencialmente se transformar em lenda para essas novas audiências. Poderíamos dizer que há pouca novidade aí se considerarmos que a indústria audiovisual (primeiro, o cinema; depois, a televisão) exerceu e exerce efetivamente um papel, mais ou menos incisivo, menos ou mais eficiente, conforme a época, na disputa geopolítica e econômica mundial e que nesta "guerra midiática" os Estados Unidos sempre se posicionaram muito bem no front.

Hoje é praticamente impossível iniciarmos o contato com uma obra audiovisual sem que tenhamos uma série de informações prévias, obtidas de modo voluntário ou não, sobre o universo que vai ser apresentado na tela. A divulgação capitaneada pelos produtores e ecoada pelos meios de comunicação repercute as principais informações da obra, seja no âmbito da produção, seja no que concerne ao conteúdo ou ainda em relação a aspectos do formato. Desse modo, sabemos com antecedência que Band of Brothers foi baseada em depoimentos dos sobreviventes da Easy Company. Portanto, quando assistimos ao primeiro episódio e vemos homens idosos em situação de entrevista, reconhecemos que aqueles são os próprios soldados veteranos. Não soubéssemos dessa informação, seria possível um momento de indecisão durante o qual vacilaríamos entre as hipóteses de estarmos vendo e ouvindo atores interpretando um texto previamente escrito e a de serem pessoas reais prestando seu depoimento autêntico. Entretanto, em Band of Brothers, quase não temos dúvida. Mesmo que não tivéssemos acesso prévio a informações sobre o formato, a não identificação daqueles homens como pessoas reais seria quase impossível. Algo do estrato da magia audiovisual nos faz crer, desde o início, que os homens postados diante da câmera rememorando parte de suas histórias são, no presente, aqueles que veremos em seguida no campo de batalha na pele de jovens atores.

A composição do plano dos depoimentos dos veteranos segue o que tem se consolidado como uma espécie de modelo padrão: enquadramento na altura no peito, o olhar do entrevistado desviando poucos centímetros 

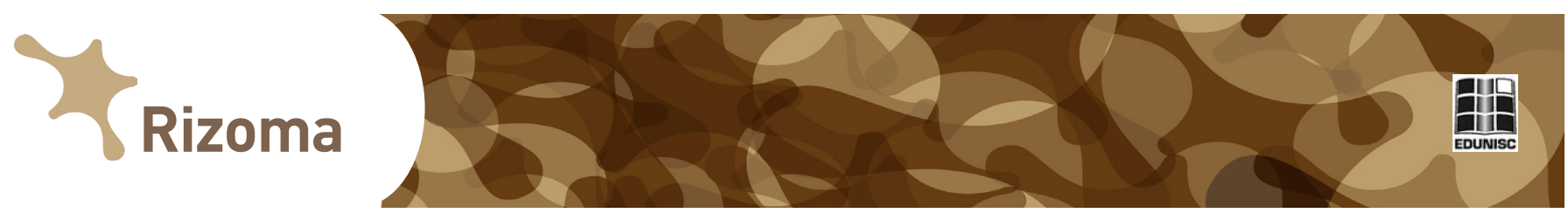

do olho da câmera e voltado para um interlocutor que está fora de quadro, posicionado ao lado da câmera. Em Band of Brothers não temos todos os elementos de uma entrevista. Faltam justamente as perguntas. Faltam a voz e a imagem do entrevistador. Principalmente a voz, uma vez que a imagem, mesmo permanecendo fora de quadro, seria substituída em boa medida pela voz que interage com o entrevistado.

No caso de Band of Brothers, reiterando, não temos nem a imagem nem a voz do entrevistador. Mas, certamente, houve a presença de um ser humano que interagiu com os homens que contaram suas histórias. Essa interação torna-se subentendida para o espectador pela angulação do olhar do entrevistado, justamente para um ser-entrevistador que deve estar postado ao lado da câmera. É imperioso registrar um paradoxo: a ausência (em imagem e áudio) do entrevistador funciona como um extraordinário autenticador de veracidade dos depoimentos. Aqueles homens contaram a história para alguém que as ouviu. Se o entrevistado olhasse diretamente para a câmera, teríamos então, um depoimento feito diretamente para nós telespectadores. E, no entanto, provavelmente tudo pareceria mais frio. Se olhassem para a máquina de filmar, também olhariam para a ausência humana, uma vez que nós, espectadores, não estamos presentes naqueles minutos de registro. Nossa presença de espectadores é posterior. É, portanto, o entrevistador presente/ausente que, magicamente, dá vida aos depoimentos. Curiosa e emblematicamente é não olhando diretamente para nós (através do olho da câmera), mas olhando para um extracampo, que o depoimento ganha em autenticidade, em grau de verdade.

A entrevista sempre constitui, afirma Cremilda Medina (1990, p. 8), "um meio cujo fim é o inter-relacionamento humano"; a entrevista, em suas diferentes aplicações, "é uma técnica de interação social, de interpenetração informativa, quebrando assim isolamentos grupais, individuais, sociais" (ibid.) e que, por isso, em geral serve à "pluralização de vozes e à distribuição democrática da informação" (ibid.). Nesse sentido, os veteranos da Easy Company, se ainda constituíam um grupo social isolado do campo da comunicação e da mídia, ganham o espaço que cabe a qualquer indivíduo, qual seja, o de tornar pública a sua história, e, mais importante, o de perpetuá-la através de um registro que tende a não ser apagado, neste caso o registro audiovisual.

A presença física dos veteranos em Band of Brothers, na idade e aparência atuais, com as marcas visíveis do envelhecimento, dialoga com o travestimento de seus personagens para o corpo dos atores jovens no campo de batalha. A memória verbalizada pelas pessoas reais no ato de entrevista ganha materialização na dimensão ficcional da produção de Spielberg e Hanks. Assim, o efeito de real é mutuamente reforçado pelos dois momentos (o dos depoimentos e o da encenação), ainda mais que a reconstrução ficcional é de um realismo extraordinário. A câmera documental, estática no momento das entrevistas, ao entrar nos campos de batalha, vai ganhar a dinamicidade exigida para "registrar" a guerra. Se para documentar a verbalização da memória é preferível uma câmera fixa, atenta às palavras, aos gestos, às 

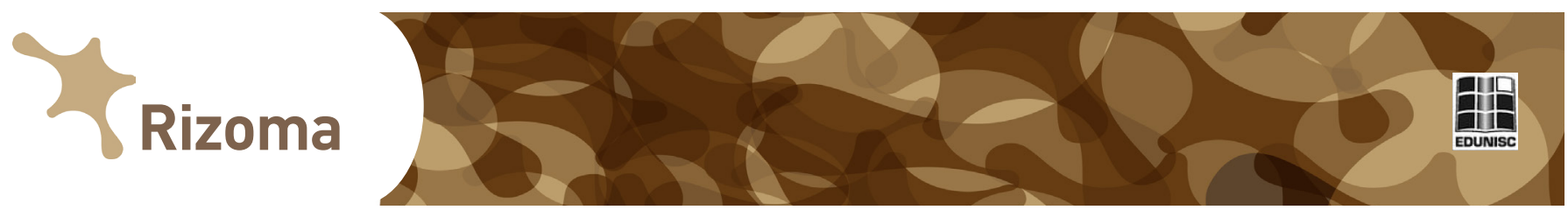

mudanças de expressões faciais do homem que lembra, no front eu preciso da câmera que acompanhe o soldado atravessando o campo inimigo para alcançar a outra trincheira, preciso da câmera que sofre os impactos de uma granada que cai perto dela.

Mas o aparato tecnológico exerce papéis diferentes quando no campo ficcional e quando no espaço documental. Se no campo da ficção, a câmera (aqui se entenda todo o aspecto técnico da encenação) joga o jogo privado e previamente estabelecido da decupagem, no espaço do documentário, a câmera está no espaço público do imponderável. Por mais que o entrevistador possa dirigir o depoimento, tudo está aberto: a memória do entrevistado vai se materializar na medida em que a interação for menos ou mais "eficiente". Edgar Morin (2007, p. 67) chama a atenção para a perturbação que ocorre na relação entrevistador/entrevistado ao dizer que "tudo na entrevista depende de uma alteração entrevistador-entrevistado, pequeno campo fechado onde se vão confrontar ou associar gigantescas forças sociais, psicológicas e afetivas". Morin também discorre sobre o conhecido poder catalisador do aparato:

\footnotetext{
Num certo sentido, a câmara permite ao mundo (espectadores) ouvir e ver alguém. Mas a câmara é também um olho - mais, ainda, um olhar de natureza mal conhecida, mas de uma intensidade prodigiosa. Como no gravador, tanto pode aumentar as forças inibidoras como as exibidoras. E dispõe de um potencial extralúcido, podendo obrigar o entrevistado a dizer a verdade. Isto pode levar a uma comédia mentirosa, porque é quando se tem a vertigem no limiar da verdade que lançamos mais facilmente o corpo perdido na fabulação. (MORIN, 2007, p. 75-76)
}

Morin aponta, portanto, para as possibilidades catalisadoras da dupla câmera/microfone, tanto em prol da retração quanto da liberação. Em ambos os casos, vislumbra-se o estabelecimento de uma encenação, deliberada ou não. Ao contrário do que possa parecer pela citação anterior, Morin não vê como algo negativo a possibilidade de fabulação impulsionada pelo aparato tecnológico. Para o autor, "graças ao poder do gravador e da câmara, a televisão e o cinema - reinos da falsa comunicação ou da comunicação imaginária - têm imensas possibilidades de comunicação, mais ricas do que na vida" (MORIN, 2007, p. 76).

Em Band of Brothers, se os depoimentos presentes nos episódios de número um a nove servem como reforço à dimensão da encenação ficcional, no décimo - e último - episódio, o documentário sobressai, justificando sobremaneira a presença dos veteranos nos episódios anteriores e conferindo, definitivamente, uma dimensão de veracidade a tudo o que vimos até aquele momento nos campos de batalha. Ocorre que nos nove episódios há uma ligação muito tênue entre os personagens vividos pelos jovens atores e os personagens reais, pois não há identificação precisa dos veteranos entrevistados. Somente no epílogo é que aparece a cartela com seus nomes. Assim, "dar nome" apenas no último episódio é um recurso que serve a dois propósitos: elevar a intensidade dramática e conferir uma contundente impressão de realidade. Na vida real, o soldado anônimo que 

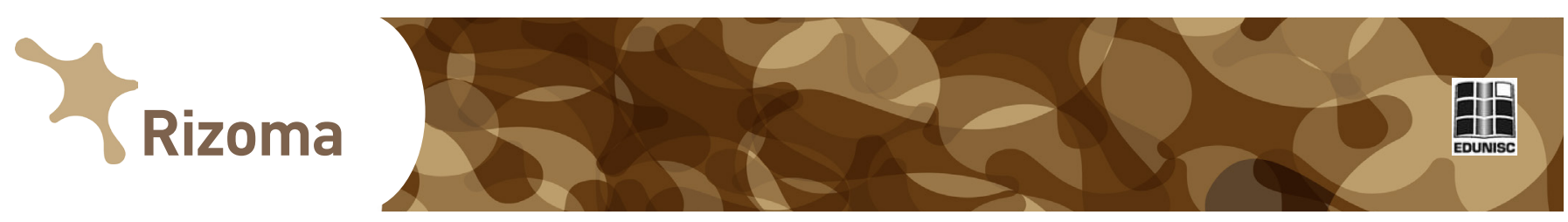

morre no campo de batalha tem seu nome lembrado apenas nas placas de monumentos, a ausência de corpo é substituída pelo nome na placa. Já em Band of Brothers, a cartela de caracteres dá nome ao corpo do soldado que sobreviveu, o corpo está presente, vivo e, ao mesmo tempo, exposto em sua finitude próxima, diante da câmera.

Assim, a conexão entre as dimensões ficcional e documental em Band of Brothers nos remete também à relação entre passado e presente. A dimensão ficcional está situada no passado, um tempo pretérito que é atualizado pelos jovens atores e materializado pela imagem e som que chegam ao espectador através da tela e dos alto-falantes. Já a dimensão documental é construída pelo "corpo atual" do ex-soldado e, nesta instância, a presença do passado se dá pela memória, que se corporifica no ato de falar e de contar.

O momento da entrevista não é, entretanto, um momento de "pura verdade". Sabemos que a encenação está sempre presente. Isto não quer dizer que os entrevistados tenham mentido. Quer dizer que a presença da câmera, por si só, confere dupla cidadania ao entrevistado: ele é personagem real e ator - e nada se pode fazer para separar os dois entes. Em outras palavras: se os jovens atores da ficção são encarnações dos soldados, tanto sobreviventes quanto mortos, os soldados que sobreviveram, agora veteranos de guerra, por sua vez, ao prestarem seu depoimento, também se tornam intérpretes: eles interpretam, em idade avançada, os jovens soldados da ficção encarnados em jovens corpos alheios.

De fato, a entrevista é sempre uma relação complexa de personagens. Num primeiro momento, entrevistador e entrevistado. Num segundo momento, a imagem e a voz do entrevistador e do entrevistado (no caso de Band of Brothers, apenas deste último) chegam aos olhos e ouvidos de um público anônimo. No entanto, não é apenas por envolver diversos personagens que a entrevista se constitui como um campo de complexidades. É também porque a entrevista "se fundamenta na fonte mais rica e mais duvidosa de todas, a palavra. Ela traz, quase sempre, o risco da dissimulação e da fabulação" (MORIN, 2007, p. 66).

Nesse sentido, Leonor Arfuch discorre sobre o paradoxo entre objetividade e subjetividade que é construído na entrevista - paradoxo no qual a objetividade poderia resultar na encenação da subjetividade a partir de certos procedimentos adotados. Nas palavras da autora:

[...] ese diálogo, que se presenta como el acceso más inmediato a una palabra auténtica, testimonial, autorizada, se enfrenta a una paradoja: su credibilidad se construye con procedimientos propios de los géneros de ficción, literarios o mediáticos. (ARFUCH, 1995, p. 24).

De acordo com a autora, os procedimentos são os seguintes: as formas de narrar, os gestos, as expressões e as entonações. Arfuch sugere que uma suposta objetividade do diálogo pode derivar curiosamente na "puesta en escena, a veces exacerbada, de la subjetividad" (ibid., p. 24). A entrevista, para Arfuch, está longe de ser um procedimento simples de coleta de informações. É, sim, uma "actividad discursiva compleja, que teje redes 


\section{Yrizoma}

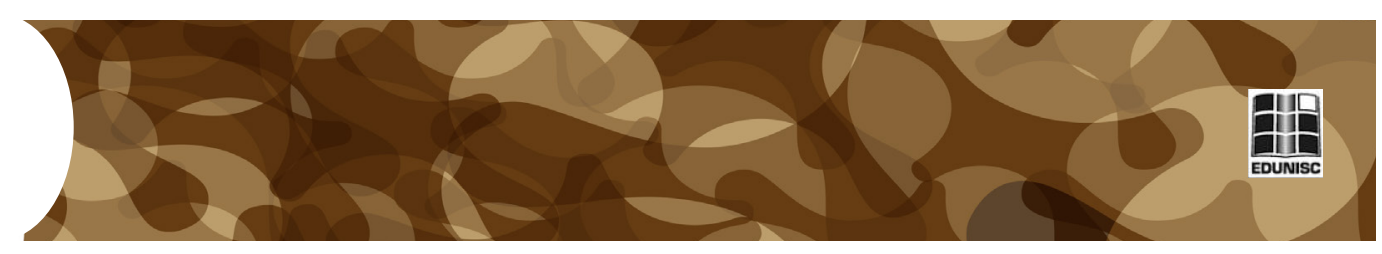

de intersubjetividad, crea obligaciones, ejerce la persuasión, el control o la violencia" (ibid., p. 49).

Não é porque colocamos um "ser real" diante da câmera que estaremos apartados da encenação. Como afirma Jacques Aumont (2008, p. 10), "a encenação está em toda a parte, nada se pode imaginar sem ela". Para Aumont, a encenação "permanece, e permanecerá na raiz de toda a arte cinematográfica imaginável, pelo menos enquanto o cinema consistir em filmar corpos humanos a exprimirem-se, a representarem, a sentirem, a viverem num quadro, num meio, num espaço e num tempo" (ibid., p. 14). Aumont não se refere exclusivamente ao documentário, mas a "toda a arte cinematográfica". Entretanto, apesar de buscar seu material de trabalho no chamado "mundo real", o documentário não consegue escapar totalmente da encenação: em maior ou menor grau, ela está sempre presente.

Se os veteranos, em seus depoimentos, tomados isoladamente, foram fiéis a sua memória, dizendo somente a verdade, nada mais que a verdade, isto não quer dizer que o "todo", que o conjunto de episódios, que a soma das partes ficcional e documental não se encadeiem para constituir a "grande encenação". O material de encenação de uma entrevista é, pois, essencialmente a memória, pelo menos na entrevista em que o interesse está na(s) história(s) do entrevistado e não na especialidade que possuam sobre algum tema. Dessa forma, entrevistar é, na maior parte das vezes, um ato que faz reviver, através da palavra, aquilo que já foi vivido pela pessoa entrevistada - ela, em geral, fala sobre um passado, seja recente, seja distante no tempo. O que a câmera e o microfone registram, então, é uma atualização do passado que ocorre pela verbalização da memória.

Portanto, em Band of Brothers, vivemos um desses raros momentos reivindicados por Morin (2007, p. 78): "Não há, na televisão e no cinema, uma falha entre o imaginário e o real, pela qual poderia se introduzir a entrevista? Ela não se tornaria operatória, se permitisse, ao mesmo tempo, a objetivação e a subjetivação?". Nessa série, a entrevista é introduzida exatamente como uma intervenção que permite "ao mesmo tempo" a objetivação e a subjetivação, um momento em que a entrevista, sutilmente, descobre a "falha entre o imaginário e o real".

\section{Referências}

ARFUCH, Leonor. La entrevista, una invención dialógica. Barcelona: Paidós, 1995.

AUMONT. Jacques. O cinema e a encenação. Tradução de Pedro Elói Duarte. Lisboa: Edições Texto \& Grafia, 2008.

MEDINA, Cremilda. Entrevista, o diálogo possível. 2ed. São Paulo: Ática, 1990. 


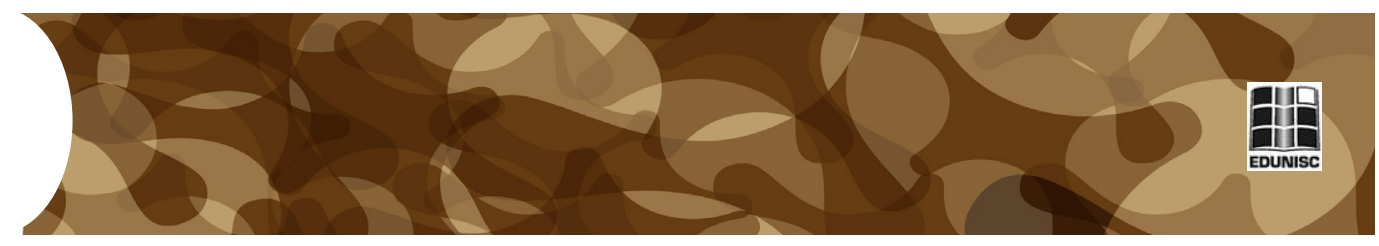

MORIN, Edgar. Da entrevista no rádio e na televisão. In: Juremir Machado da Silva (org.). As duas globalizações: complexidade e comunicação, uma pedagogia do presente. 3. ed. Porto Alegre: Sulina, Sulina, EDIPUCRS, 2007, p. 61-79.

NICHOLS, Bill. Introdução ao documentário. Tradução de Mônica Saddy Martins. Campinas: Papirus, 2005.

\section{Séries citadas}

TWIN Peaks. Criação: David Lynch; Mark Frost. Estados Unidos, ABC, 1990-1991, 2 temp. 30 ep., son., color.

BAND of Brothers. Criação: Steven Spielberg, Tom Hanks; Stephen Ambrose. Estados Unidos, HBO, 2001, 1 temp. 10 ep., son., color. 